\title{
The unfolded protein response induced by Tembusu virus infection
}

\author{
Dongmin Zhao ${ }^{1,2^{*}+}$ (D) Jing Yang ${ }^{1,2 \dagger}$, Kaikai Han ${ }^{1,2}$, Qingtao Liu ${ }^{1,2}$, Huili Wang ${ }^{3}$, Yuzhuo Liu ${ }^{1,2}$, Xinmei Huang ${ }^{1,2}$, \\ Lijiao Zhang ${ }^{1,2}$ and Yin $\mathrm{Li}^{1,2^{*}}$
}

\begin{abstract}
Background: Tembusu virus (TMUV), classified in the genus Flavivirus, causes reduced egg production and neurological problems in poultry. Flavivirus replication depends on the host endoplasmic reticulum (ER) and induces ER stress that leads to activation of the cellular unfolded protein response (UPR), an important signalling pathway that regulates many biological functions involved in viral pathogenesis and innate immunity. However, the mechanism of TMUV-induced UPR activation remains unclear.

Results: In this study, we systematically investigated the three UPR pathways in TMUV-infected BHK-21 cells. Our results showed that expression of glucose-related protein 78 (GRP78) and GRP94 was upregulated during the course of TMUV infection. We then demonstrated that TMUV activated the PERK pathway in the early stage of infection, resulting in upregulation of ATF4, GADD34 and CHOP, with CHOP induction leading to caspase-3 activation. We also found the IRE1 pathway to be activated, leading to splicing of $X$ box binding protein 1 (XBP1) mRNA and enhanced expression of p58 $8^{\text {IPK }}$. Finally, we observed increased expression of ATF6 and activity of ER stress-response elements, suggesting stimulation of the ATF6 pathway. In addition, ATF6 pathway activation correlated with the induction of downstream chaperones calnexin, calreticulin, ERp57 and PDI. UPR activity was also observed by the marked elevation in GRP78 and sXBP1 levels in TMUV-infected DF-1 cells.

Conclusions: This is the first report that TMUV infection-induced ER stress activates three branches of the UPR, and these results lay the foundation for elucidating the pathogenesis of TMUV and understanding the inherent mechanism of TMUV infection as well as the host response.
\end{abstract}

Keywords: Tembusu virus, Endoplasmic reticulum stress, Unfolded protein response, Activation

\section{Background}

Tembusu virus (TMUV) is an avian-origin flavivirus that is the causative agent of Tembusu virus disease, a complex pathology of avians associated with a decline in egg production, a decrease in food intake, paralysis and ovarian haemorrhage [1]. Infection and morbidity rates can reach $100 \%$, with mortality of $5-30 \%$, depending on secondary bacterial infections. The prevalence of TMUV has become a severe problem and has seriously hampered the development of the poultry breeding industry in China [2].

\footnotetext{
*Correspondence: zhaodongmin126@126.com; muziyin08@163.com; muziyin08@163.com

${ }^{+}$Dongmin Zhao and Jing Yang contributed equally to this work.

${ }^{1}$ Institute of Veterinary Medicine, Jiangsu Academy of Agricultural Sciences,

Jiangsu Province 210014, People's Republic of China

Full list of author information is available at the end of the article
}

As with other Flaviviridae viruses, the positive-sense, single-stranded RNA genome of TMUV serves as messenger RNA that is translated into a polyprotein consisting of three structural (capsid, membrane and envelope protein) and seven nonstructural (NS1, NS2a, NS2b, NS3, NS4a, NS4b and NS5) proteins. The polyprotein is subsequently processed into functional products by viral and host proteases. Flaviviruses depend on the endoplasmic reticulum (ER) for their life cycle and are termed ER-tropic viruses [3, 4].

The ER consists of a membranous, interconnected network with complex dynamic construction that is indispensable for various essential cellular processes [5]. For example, various specialized functions, such as calcium homeostasis and intracellular signal transduction, occur in the ER, and it acts as the major site for the synthesis and folding of transmembrane and secreted proteins [6].

(c) The Author(s). 2019 Open Access This article is distributed under the terms of the Creative Commons Attribution 4.0 International License (http://creativecommons.org/licenses/by/4.0/), which permits unrestricted use, distribution, and 
Indeed, nearly one-third of proteins in the secretory pathway are folded and mature in the ER [5]. To maintain quality control and ensure the correct folding of secreted proteins, ER homeostasis is tightly regulated, and the accumulation of misfolded proteins in the ER lumen leads to defects in protein folding and modification, a condition known as ER stress [7].

To restore ER homeostasis during ER stress, cells invoke the unfolded protein response (UPR), which aims to decrease the arrival of newly synthesized proteins and to enhance the functional capacity of the ER. The former is achieved via phosphorylation of eukaryotic translation initiation factor 2 (eIF2) and the latter by upregulating the transcription of chaperones and folding enzymes [8]. The UPR consists of three distinct pathways: the protein kinase RNA-like ER kinase (PERK), the inositol-requiring enzyme 1 (IRE1), and the activating transcription factor 6 (ATF6) pathways. In the PERK pathway, PERK is activated by ER stress and phosphorylates the $\alpha$ subunit of eIF2 (eIF2 $\alpha$ ) at serine residue 51 [9], thereby preventing protein synthesis by repressing mRNA translation. Paradoxically, phospho-eIF2 $\alpha$ promotes expression of activating transcription factor 4 (ATF4) [10], a factor that stimulates transcription of C/EBP-homologous protein (CHOP), which in turn induces expression of growth arrest and DNA damage 34 (GADD34) and will target protein phosphatase 1 (PP1) to dephosphorylate eIF2 $\alpha$ [11]. Persistent ER stress leads to attenuation or termination of eIF2a phosphorylation and downstream signalling. The IRE1 and/ or ATF6 pathway is activated as a result of the restoration of protein synthesis [8]. Activation of the IRE1 (type I ER-resident transmembrane protein) pathway is driven by trans-autophosphorylation, whereby phosphorylated IRE1 cleaves the 26-bp intron from the XBP1 (X-boxing binding protein-1) mRNA. This spliced form of XBP1 increases expression of its downstream target genes, including $\mathrm{p} 58^{\mathrm{IPK}}$ and several UPR chaperones $[4,12]$. The continuous presence of spliced XBP1 also results in the transfer of UPR signalling from the PERK to the IRE1 and/or ATF6 pathways [12]. During ER stress, ATF6 passes from the ER to the Golgi where it is cleaved by proteases. This active form of ATF6 translocates to the nucleus and activates expression of ER chaperone genes involved in protein folding via binding to ER stress-response elements (ERSEs) [13-16]. Such increased expression of chaperones, including glucoseregulated protein 78 (GRP78), GRP94, calnexin, calreticulin, ER protein $57 \mathrm{kDa}$ (ERp57) and protein disulfide isomerase (PDI), promotes the correct folding of newly synthesized proteins [17]. In unstressed cells, GRP78 binds to the luminal domains of PERK, IRE1 and ATF6 to maintain these proteins in an inactive state $[18,19]$. When unfolded or misfolded proteins accumulate in the ER, GRP78 is released from the three UPR sensors and preferentially binds to unfolded or misfolded proteins, resulting in activation of UPR sensors and initiation of UPR signalling cascades [20].

Previous studies have shown that flavivirus infection can activate one or more of the three branches of the UPR. For example, activation of UPR pathways by Dengue virus (DENV) was found to be dependent on the time of infection: early PERK activation and eIF $2 \alpha$ phosphorylation were triggered in the early stage of DENV infection; during mid and late stages, the PERK pathway was switched off and the IRE1 and ATF6 pathways activated, respectively [3]. In the case of West Nile virus (WNV), infection with an attenuated strain prevented PERK pathway activation, whereas a highly neurovirulent strain upregulated all three branches of the UPR [21, 22]. As another example, Japanese encephalitis virus (JEV) infection initiated the UPR to promote chaperone expression in cells naturally sensitive to JEV-induced cell death [23]. Additionally, Zika virus (ZIKV) infection, which causes microcephaly in newborns and neurodevelopment abnormalities in adults, activates the IRE1-XBP1 and ATF6 pathways to respond to ER stress in vitro and in vivo [24]. Usutu virus (USUV) infection also induces the UPR, as revealed by the induction of XBP1 mRNA splicing following USUV infection $[25,26]$. Furthermore, Tick-borne encephalitis virus (TBEV) triggers IRE1 and ATF6 pathway activation of the UPR, and an IRE1 inhibitor (3,5-dibromosalicylaldehyde) significantly limits TBEV replication in Vero E6 cells, suggesting that this UPR inhibitor might serve as a new therapeutic strategy against TBEV infection [4].

The ER not only provides a platform for flavivirus replication but also for the membrane components for viral particles [25, 27]. Although viral replication leads to the activation of UPR signalling, some facets of the UPR may be beneficial for virus infection. In fact, viruses have evolved to utilize the UPR to promote viral translation and persistence in infected cells $[25,28]$. Studies on the DENV envelope protein showed interaction with the ER chaperones GRP78, calreticulin and calnexin, facilitating proper folding and assembly of dengue proteins, and knocking down the expression of these three chaperones resulted in significantly decreased virus production [29]. In addition, by preventing cell death and inhibiting innate immune responses, the ATF6 pathway was found to be necessary for $\mathrm{WNV}_{\mathrm{KUN}}$ replication, and ATF6 deficiency led to impairment of $\mathrm{WNV}_{\mathrm{KUN}}$ production, increased CHOP activation and early apoptosis as a result of $\mathrm{WNV}_{\mathrm{KUN}}$ replication [30].

Despite elementary investigations of the pathogenicity of TMUV [31], the ER stress and UPR induced by TMUV infection remain unclear. Therefore, to explore UPR activation during TMUV infection, we systematically examined induction of the three branches of the UPR and measured the expression levels of UPR-related 
genes. This work provides new insight into TMUV-induced activation of the UPR.

\section{Results}

TMUV infection results in the induction of GRP78 and GRP94 expression

To evaluate the UPR in TMUV infection, the infectivity of TMUV in BHK-21 cells was first determined. Cells were infected with TMUV at an MOI of 3, and viral titres in the supernatant were determined using the plaque assay. The results showed that viral titres increased during the post-infection period, at $48 \mathrm{~h}$ (Fig. 1a).

As the UPR is characterized by upregulated expression of chaperones GRP78 and GRP94 [23], the expression levels of GRP78 and GRP94 were analysed during the course of TMUV infection, under the same infection conditions, by real-time RT-PCR and western blotting. As shown in Fig. 1b and c, GRP78 and GRP94 expression was persistently upregulated from 24 to $48 \mathrm{~h}$ post-infection compared to mock-infected cells. These results demonstrate that TMUV infection potentially induces ER stress in BHK-21 cells.

\section{The PERK pathway is activated during TMUV infection}

To determine the phosphorylation status of eIF $2 \alpha$ during TMUV infection, phosphorylated and total eIF2 $\alpha$ were detected by western blotting for $48 \mathrm{~h}$. As shown in Fig. 2a, compared with mock-infected cells, the levels of phosphorylated eIF $2 \alpha$ in infected cells increased significantly at $12 \mathrm{~h}$ post-infection, reached a peak at $36 \mathrm{~h}$ and then decreased to a level lower than that of the mock-infected cells at $48 \mathrm{~h}$ post-infection. No significant change in tubulin or total eIF $2 \alpha$ expression was observed in either mock- or TMUV-infected cells. Four
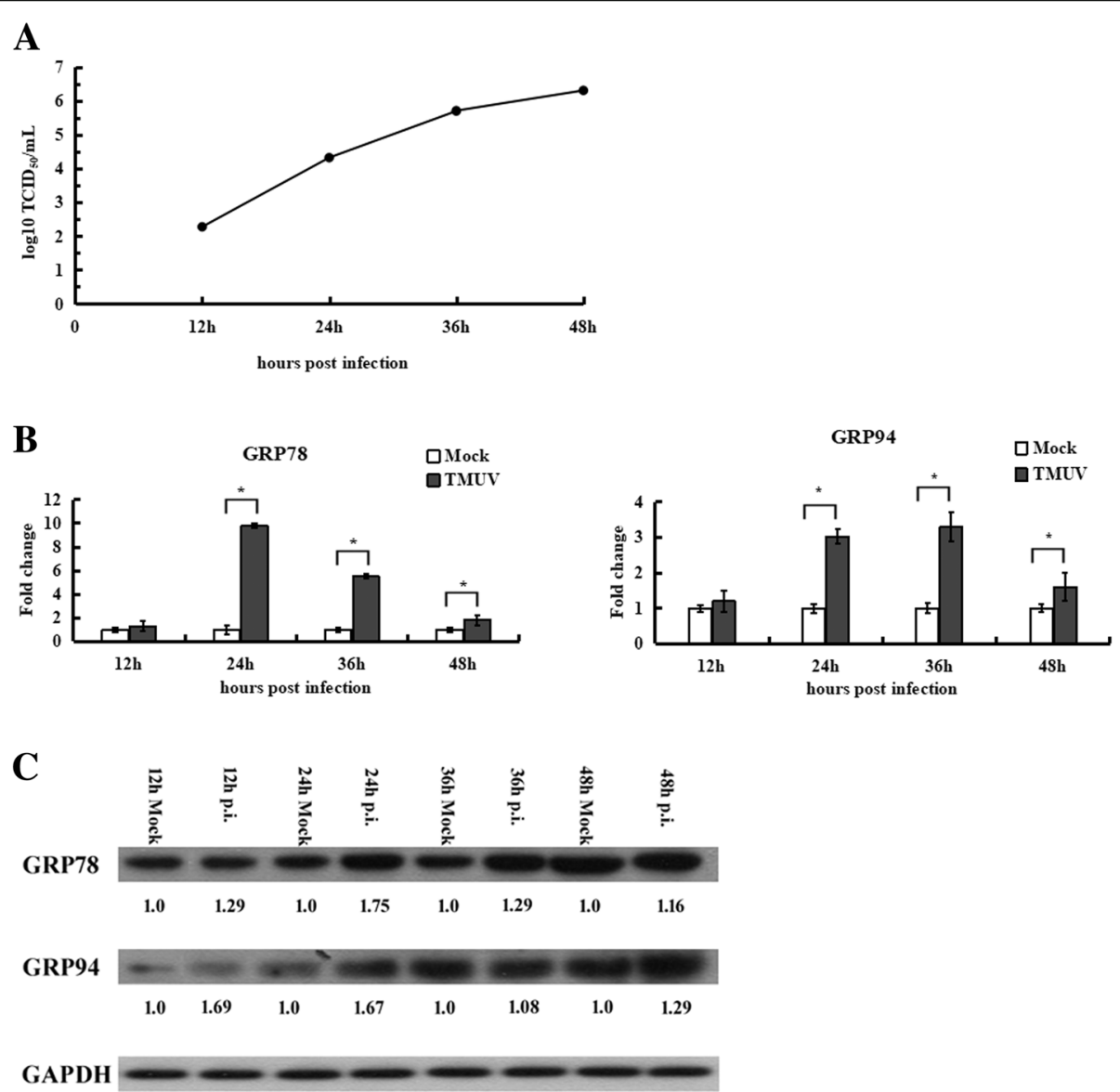

Fig. 1 Increased GRP78 and GRP94 expression in TMUV-infected BHK-21 cells. a, The replication profile of TMUV in BHK-21 cells. b, Expression of GRP78 and GRP94 was determined by real-time RT-PCR. The Y axis represents the fold change of target gene expression in TMUV-infected cells versus that in mock-infected cells. Statistical analyses were performed using Student's $t$ test in this and in all subsequent figures. The data are expressed as the means $\pm S D$ of results from three independent experiments. The asterisk indicates a statistically significant difference ( $p<0.05)$. $\mathbf{c}$, Protein levels of GRP78 and GRP94 were examined by western blotting. The intensities of bands were determined using IMAGE J software, and the data represent ratios of TMUV-infected cells to mock-infected cells at the indicated time points 

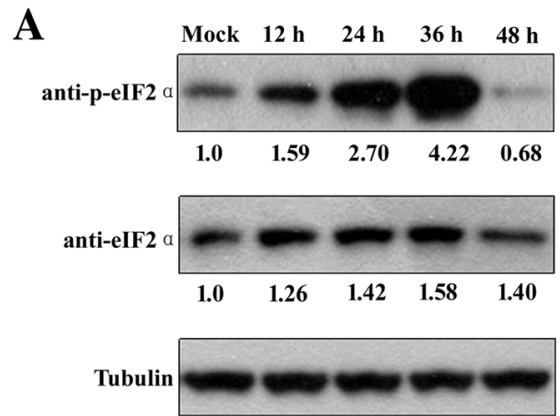

C

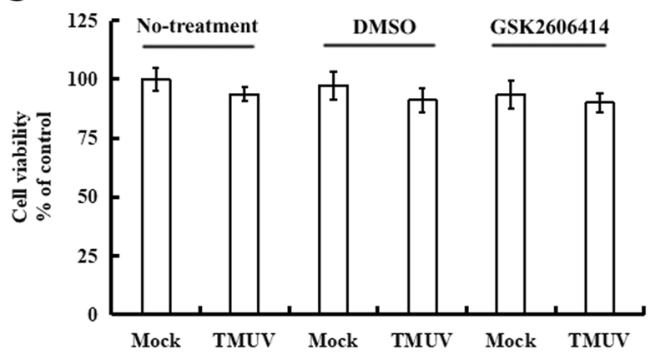

E

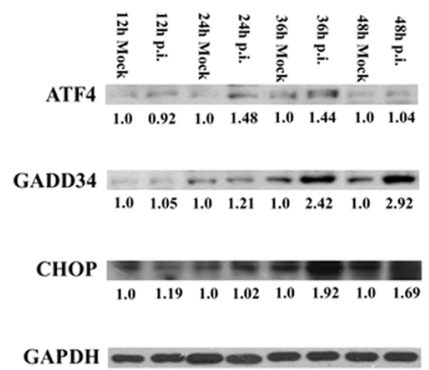

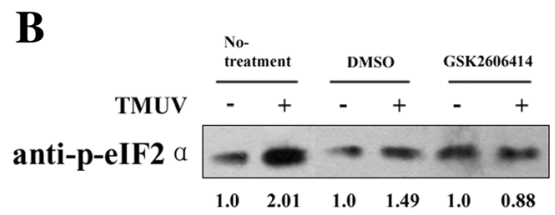

anti-eIF2 a

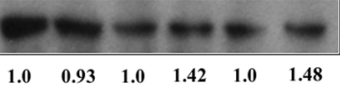

GAPDH

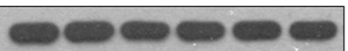

D
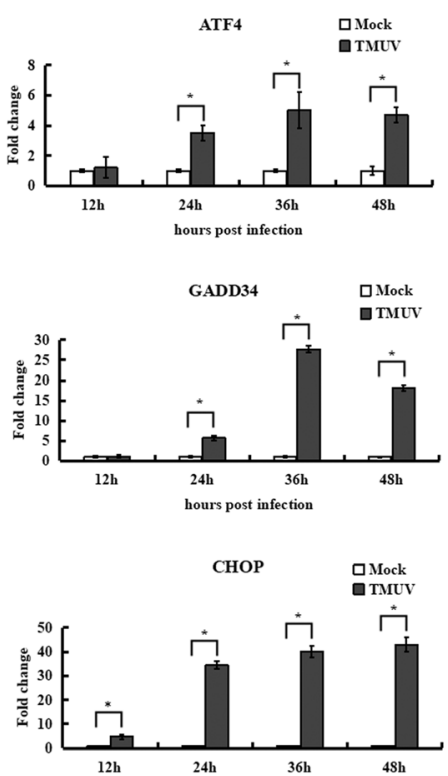

Fig. 2 Activation of the PERK pathway by TMUV infection. a, Phosphorylation of elF2a was detected by western blotting. Mock- or TMUV-infected BHK-21 cells were lysed and harvested at the indicated time points. Phosphorylated or total elF2a was analysed by western blotting using corresponding antibodies. Tubulin was used as an internal control. The intensities of bands were determined using IMAGE J software, and the data represent ratios of TMUV-infected cells to mock-infected cells at the indicated time points. $\mathbf{b}$, Inhibition of elF2a phosphorylation in BHK-21 cells by treatment with the PERK inhibitor GSK2606414. Cells were harvested at $24 \mathrm{~h}$ post-infection and subjected to western blotting. The intensities of phospho-elF2a and elF2a were determined using IMAGE J software, and the results are shown as ratios of TMUV-infected cells to mock-infected cells. c, BHK-21 cells were infected with TMUV at an MOI of 3 and treated with 1 MM GSK2606414 or the corresponding level of DMSO or were not treated. Untreated mock-infected BHK-21 cells were used as a control. Twenty-four hours post-infection, cell viability was assessed using the CCK-8 kit. The data are expressed as the means \pm SD of results from three independent experiments. $\mathbf{d}$, Real-time RT-PCR analysis of components of the PERK pathway during a time course of TMUV infection. The $Y$ axis shows the fold change of target gene expression in TMUV-infected cells, as determined using the comparative CT method. The data are expressed as the means \pm SD of results from three independent experiments. ${ }^{*} p<0.05$ vs. mock-infected cells. e, Protein levels of ATF4, GADD34 and CHOP were examined by western blotting. The intensities of bands were determined using IMAGE J software, and the data represent ratios of TMUV-infected cells to mock-infected cells at the indicated time points

eIF2 $\alpha$ kinases are involved in eIF2 $\alpha$ phosphorylation: PERK, double-stranded RNA protein kinase R (PKR), heme-regulated inhibitor kinase (HRI) and general control non-derepressible-2 (GCN2), which are activated to respond to the accumulation of unfolded proteins, the presence of double-stranded RNA during viral infection, heme deficiency and amino acid starvation, respectively $[3,8]$. To further clarify whether eIF $2 \alpha$ phosphorylation is mediated by PERK, the selective PERK inhibitor GSK2606414 was employed to investigate the role of PERK during the early stage of TMUV infection. The results showed that GSK2606414 reduced the level of 
phospho-eIF $2 \alpha$ at $1 \mu \mathrm{M}$, the dose completely inhibiting PERK activity [32] (Fig. 2b). As treatment with GSK2606414 might affect cell viability and ultimately impact experimental results, the CCK-8 assay was performed, and we found that GSK2606414 did not significantly affect the viability of BHK-21 cells (Fig. 2c). The above results suggested that PERK is required for the phosphorylation of eIF2a and that the PERK pathway is stimulated in response to TMUV-induced ER stress.

Previous studies have demonstrated that persistent eIF2 $\alpha$ phosphorylation selectively increases expression of ATF4 [10]. In this study, ATF4 expression increased significantly after $12 \mathrm{~h}$ post-infection, resulting in the induction of CHOP and in turn expression of GADD34 (Fig. 2d and e). CHOP is considered an important specific factor in the ER stress-induced apoptosis pathway [33], and the transcriptional expression and activity of caspase-3, -8 and -9 were determined using real-time RT-PCR and enzyme assay kits, respectively. As shown in Fig. 3, no evident change in caspase-8 and caspase-9 occurred in cells at $48 \mathrm{~h}$ post-infection compared to mock-infected cells. However, a similar trend for caspase-3, remaining unchanged at $24 \mathrm{~h}$ post-infection but increasing significantly at $36 \mathrm{~h}$ post-infection, compared to the mock-infected cells was observed. These data suggest that TMUV infection leads to the induction of apoptosis and that ER stress-mediated apoptotic signals ultimately converge on caspase- 3 .

\section{TMUV infection activates the IRE1 pathway}

In the IRE1 pathway, autophosphorylated IRE1 removes a 26-bp intron from the unspliced XBP1 (uXBP1) mRNA, the translation of which produces a stable, active 371-amino acid isoform, spliced XBP1 (sXBP1), that binds to the ERSE sequence of many UPR target genes, leading to transcription of ER-chaperone proteins [34]. Splicing of uXBP1 results in loss of the Pst I restriction site located in the intron [35]. At $36 \mathrm{~h}$ and $48 \mathrm{~h}$ post-infection, the 530-bp RT-PCR products from TMUV-infected cells were found to be resistant to Pst I digestion, whereas at $12 \mathrm{~h}$ and $24 \mathrm{~h}$ post-infection, the RT-PCR products from TMUV-infected cells were
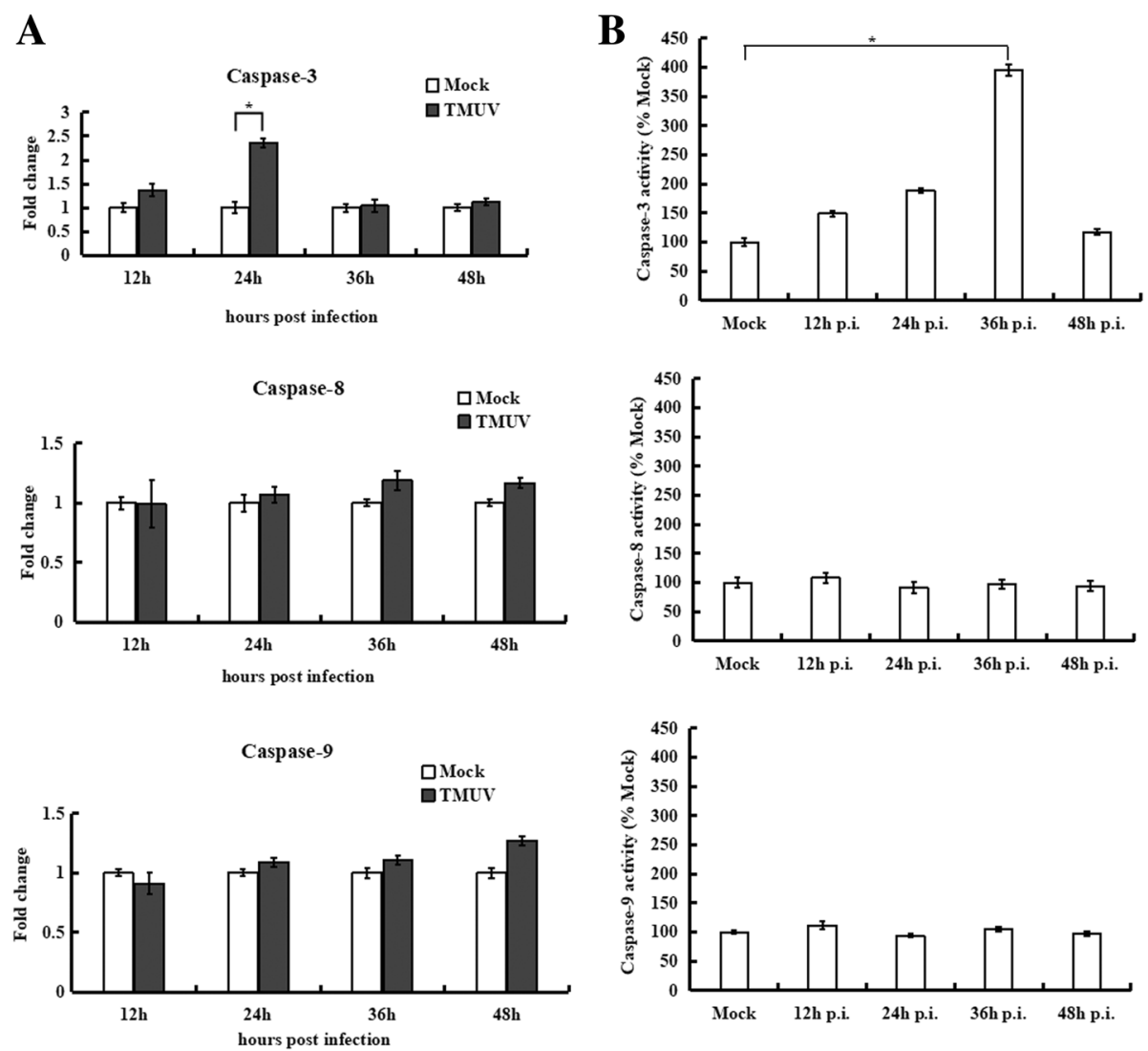

Fig. 3 Analysis of caspases in TMUV-infected BHK-21 cells. a, Transcriptional expression of caspases was determined by real-time RT-PCR. The Y axis shows the fold change of target gene expression in TMUV-infected cells, as determined by the comparative CT method. b, Caspase activity was determined using colorimetric assays. The data are expressed as the means \pm SD of results from three independent experiments. ${ }^{*} p<0.05$ vs. mock-infected cells 

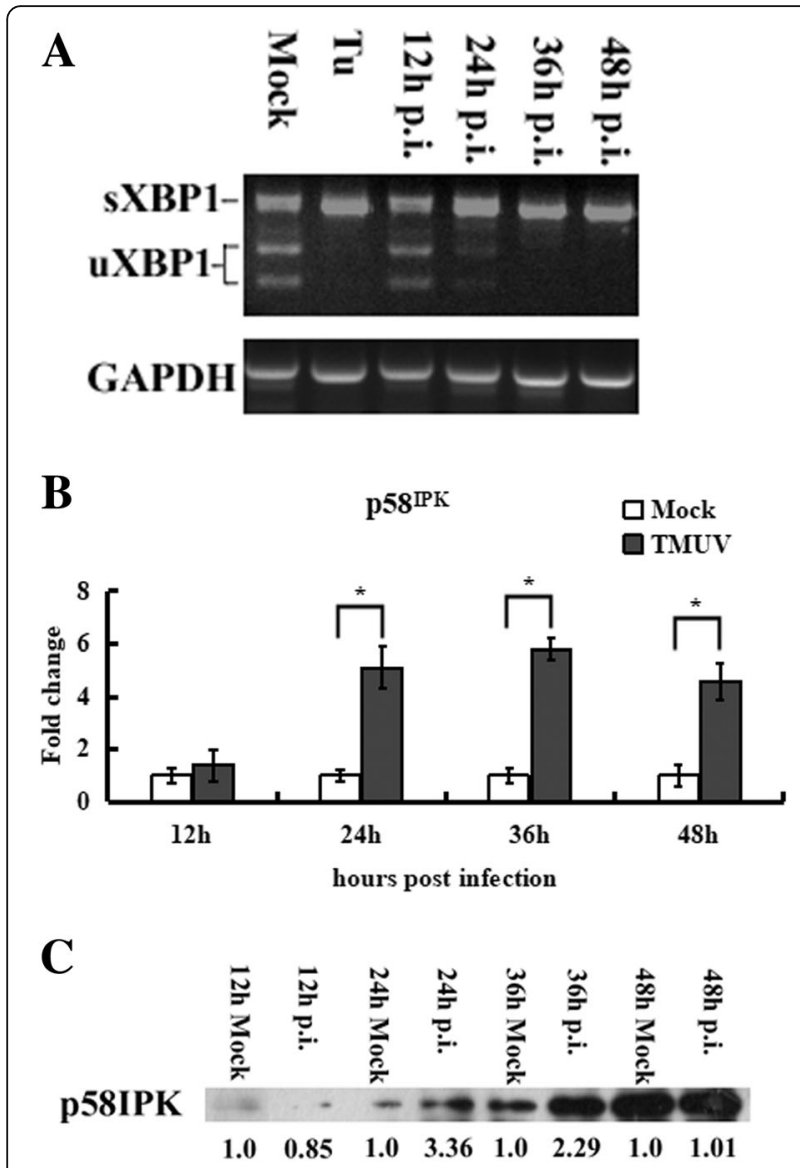

\section{GAPDH}

Fig. 4 TMUV infection induces XBP1 mRNA splicing and leads to p58IPK upregulation. a, XBP1 mRNA was amplified by RT-PCR and digested by Pst I. BHK-21 cells were mock-infected or infected with TMUV. Cells treated with $1 \mu \mathrm{M}$ tunicamycin (Tu) for $12 \mathrm{~h}$ were used as a positive control. At the indicated times after infection, XBP1 mRNA was amplified by RT-PCR using XBP1-specific primers, after which the XBP1 fragment was subjected to Pst I digestion, and the products were separated by $1 \%$ agarose gel electrophoresis. b, p58IPK upregulation was detected by real-time RT-PCR. The $Y$ axis shows the fold change of target gene expression in TMUV-infected cells, as determined by the comparative CT method. The data are expressed as the means $\pm S D$ of results from three independent experiments. ${ }^{*} p<0.05$ vs. mock-infected cells. c, The protein level of p58IPK was examined by western blotting. The intensities of bands were determined using IMAGE J software, and the data represent ratios of TMUV-infected cells to mock-infected cells at the indicated time points

digested by Pst I to generate 317-bp and 213-bp fragments (Fig. 4a). p58 ${ }^{\mathrm{IPK}}$ is a downstream gene transcriptionally induced by sXBP1 [36], and as shown in Fig. 4b and $\mathrm{c}$, significantly increased transcription of $\mathrm{p} 58^{\mathrm{IPK}}$ was detected in cells infected with TMUV. The results above show that TMUV activates the IRE1 pathway.
TMUV infection activates the ATF6 pathway

During ATF6 activation, the full-length protein (90 $\mathrm{kDa}$ ) is cleaved to release an active $50-\mathrm{kDa}$ variant of ATF6 comprising the N-terminus [37, 38]. To further explore whether TMUV infection induces the ATF6 branch of the UPR, ATF6 expression was detected by western blotting using an antibody against full-length ATF6. As shown in Fig. 5a, TMUV infection slightly increased the level of ATF6 at $12 \mathrm{~h}$ and $24 \mathrm{~h}$ post-infection. A dual-luciferase reporter assay was then carried out to evaluate the transcriptional activity of ATF6 and ERSE. Forty-eight hours after transfection, cells were infected with TMUV, and the results showed slightly increased (1.5-fold) luciferase activity in cells transfected with pGM-ATF6-Lu compared with that of mock-infected cells. In addition, cells transfected with pGM-ERSE-Lu exhibited a 3.8-fold increase in luciferase activity compared with that in mock-infected cells (Fig. 5b). Furthermore, expression of ATF6-induced chaperones, including calnexin, calreticulin, ERp57 and PDI, was analysed by real-time RT-PCR and western blotting. Compared with cells mock-infected with TMUV, expression of ATF6-induced chaperones was upregulated from $12 \mathrm{~h}$ to $24 \mathrm{~h}$ post-infection and then returned to the level of the mock control (Fig. 5c and d). These results indicate that TMUV infection activates the ATF6 pathway.

\section{UPR induction in TMUV-infected DF-1 cells}

Considering that TMUV is an avian pathogen, UPR induction was further assessed in TMUV-infected DF-1 cells by real-time RT-PCR (Fig. 6). At $24 \mathrm{~h}$ post-infection, expression of GRP78 and GRP94 showed a significant (3-fold) induction and a near 2-fold increase, respectively. Using primers that specifically detect the spliced or unspliced form of XBP1, we found that XBP1 splicing was increased approximately 10 -fold at $48 \mathrm{~h}$ post-infection; only a modest induction ( 2-fold increase) of unspliced XBP1 was observed at $24 \mathrm{~h}$ post-infection. Conversely, no ATF4 expression change was observed over a 48-h time course. The results of the dual luciferase reporter assay demonstrated that transfection with pGM-ATF6-Lu resulted in a 2.4-fold increase in luciferase activity at $48 \mathrm{~h}$ post-infection compared with the activity of mock-infected cells. At $12 \mathrm{~h}$ post-infection, the cells transfected with pGM-ERSE-Lu exhibited a 1.4-fold increase in luciferase activity compared with that in mock-infected cells. These data suggest that TMUV induction of the UPR in DF-1 cells primarily occurs via the IRE1 pathway, with some induction of the ATF6 pathway.

\section{Discussion}

The viral life cycle consists of a series of events involving entry, protein synthesis and modification, genome replication and maturation. Viruses utilize the 


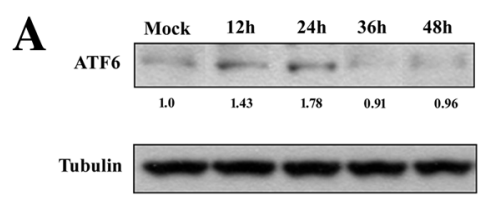

B

pGM-ATF6-Lu
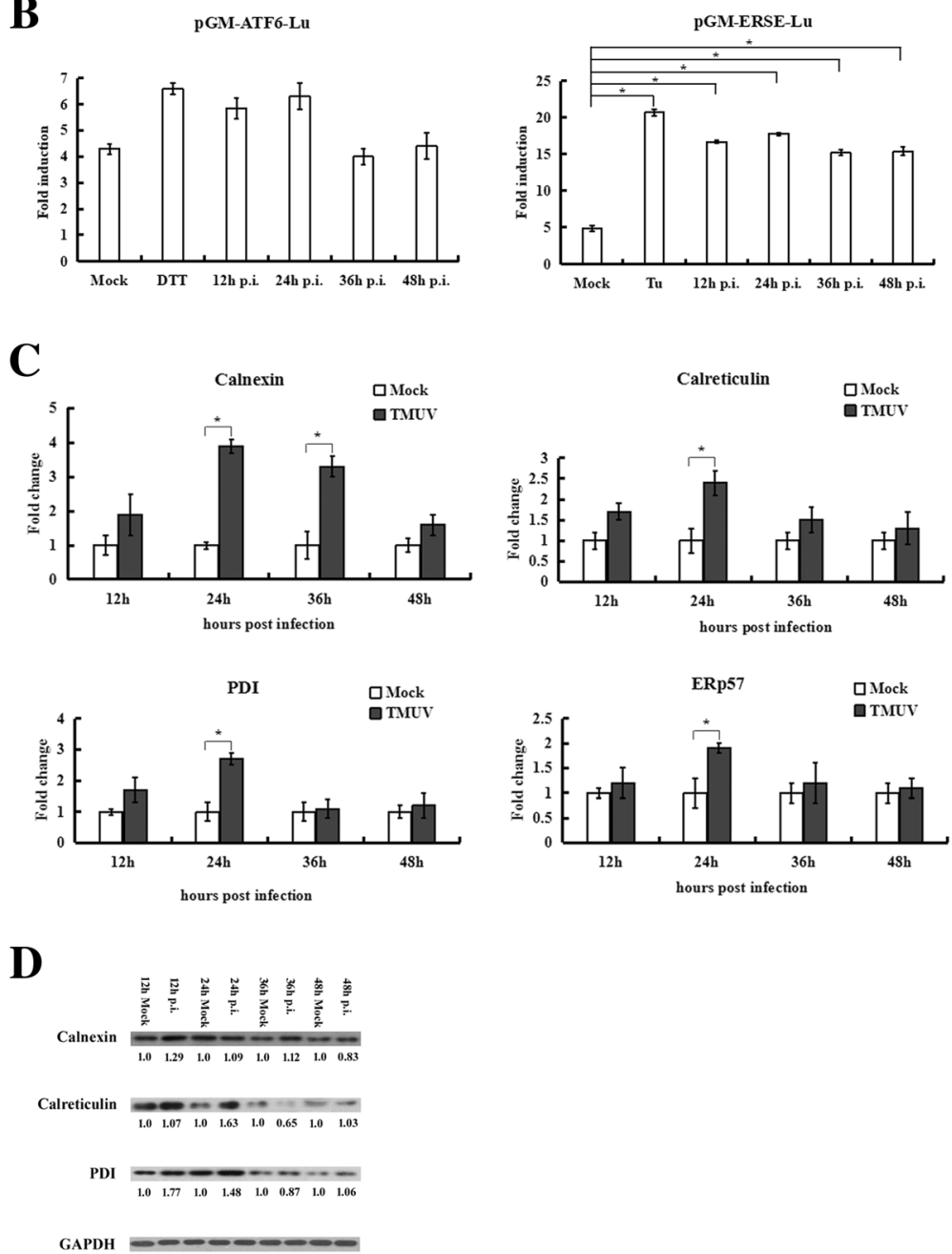

Fig. 5 Analysis of the ATF6 pathway during TMUV infection. a, Expression of ATF6 after TMUV infection was examined by western blotting using an antibody specific for full-length ATF6. Tubulin was used as an internal control. The intensities of bands were determined using IMAGE J software, and the data represent ratios of TMUV-infected cells to mock-infected cells at the indicated time points. $\mathbf{b}$, Activation of the ATF6 pathway was monitored by a dual luciferase reporter gene assay. BHK-21 cells were transfected with pGM-ATF6-Lu or pGM-ERSE-Lu. Firefly luciferase activity was normalized based on Renilla luciferase activity in cells cotransfected with pRL-TK. After $48 \mathrm{~h}$ of transfection, the cells were mock infected or infected with TMUV. Cells treated with $1 \mu \mathrm{M}$ tunicamycin for $12 \mathrm{~h}$ or $2.5 \mathrm{mM}$ dithiothreitol (DTT) for $7 \mathrm{~h}$ were used as a positive control. Cells were collected at the indicated time points and assayed for firefly and Renilla luciferase activities. The values represent the means \pm SD of results from three independent experiments. $\mathbf{c}$, Expression of chaperones induced by TMUV infection. The $Y$ axis shows the fold change of target gene expression in TMUV-infected cells, as determined by the comparative CT method. The data are expressed as the means \pm SD of results from three independent experiments. ${ }^{*} p<0.05$ vs. mock-infected cells. d, Protein levels of chaperones were examined by western blotting. The intensities of bands were determined using IMAGE J software, and the data represent ratios of TMUV-infected cells to mock-infected cells at the indicated time points

mechanisms and resources of host cells to complete their entire replication cycle [39]. During this process, quantities of viral proteins are synthesized within infected cells, leading to the accumulation of unfolded or misfolded proteins in the ER and resulting in the activation of ER stress [4]. To cope with ER stress, 
A
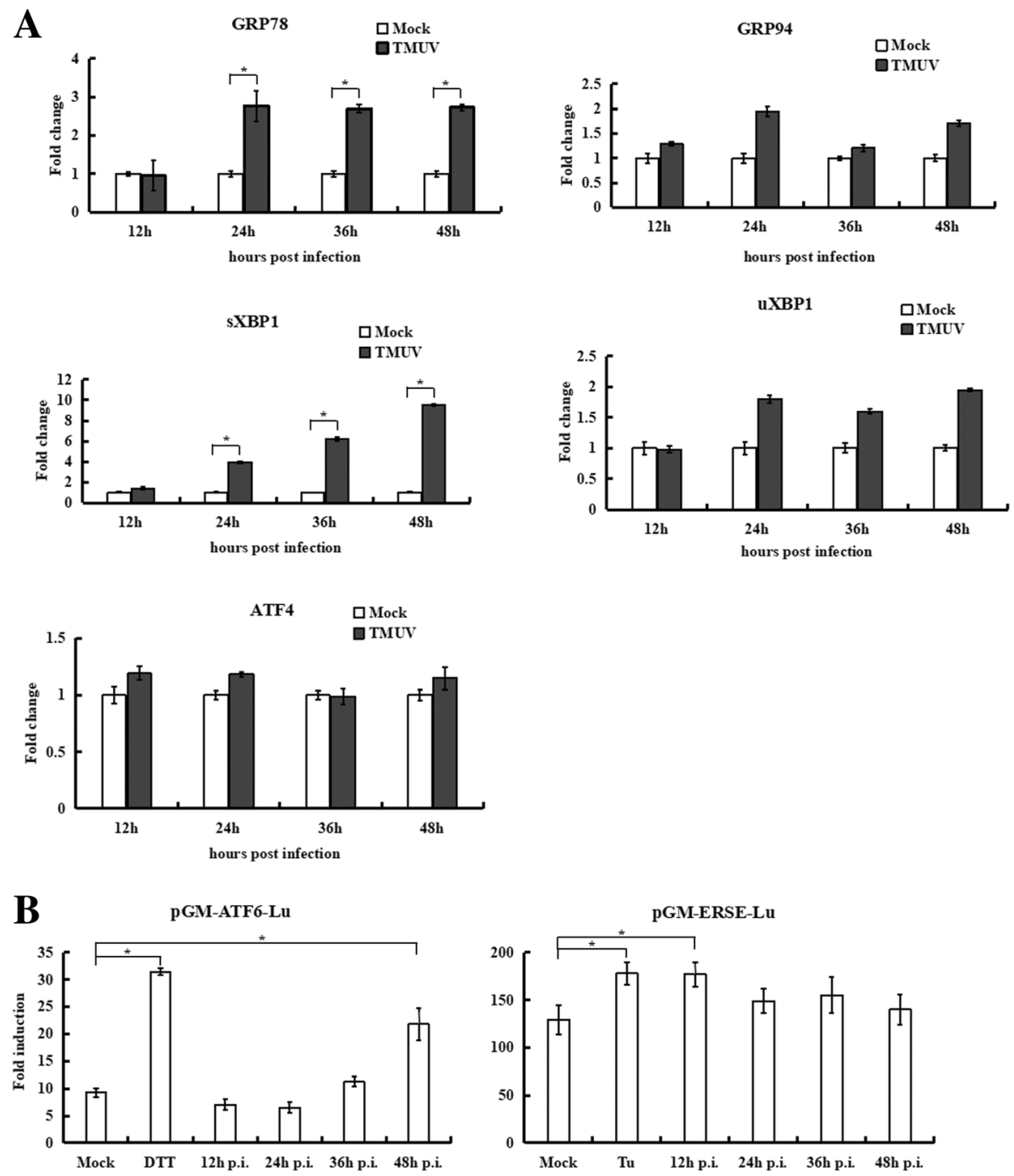

Fig. 6 The UPR is induced by TMUV infection in DF-1 cells. a, Expression of GRP78, GRP94 sXBP1, uXBP1 and ATF4 was determined by real-time RT-PCR. The $Y$ axis represents the fold change of target gene expression in TMUV-infected cells versus that in mock-infected cells. b. Activation of the ATF6 pathway in TMUV-infected DF-1 cells was monitored by a dual luciferase reporter gene assay. DF-1 cells were transfected with PGM-ATF6-Lu or pGM-ERSE-Lu. Firefly luciferase activity was normalized based on Renilla luciferase activity in cells cotransfected with pRL-TK. After $48 \mathrm{~h}$ of transfection, the cells were mock infected or infected with TMUV. Cells treated with $1 \mu \mathrm{M}$ tunicamycin for $12 \mathrm{~h}$ or $2.5 \mathrm{mM}$ dithiothreitol (DTT) for $7 \mathrm{~h}$ were used as a positive control. Cells were collected at the indicated time points and assayed for firefly and Renilla luciferase activities. The values represent the means \pm SD of results from three independent experiments. The asterisk indicates a statistically significant differences $(p<0.05)$

three sensors, PERK, IRE1 and ATF6, are stimulated to reduce expression of new proteins, to facilitate the folding of proteins and to enhance the degradation of misfolded proteins, also known as the UPR [18].

Flavivirus particles are assembled and mature in the ER lumen [40], and several flaviviruses, including JEV, DENV, WNV and TBEV, have been reported to stimulate the UPR to lessen the ER stress caused by the accumulation of viral proteins [4, 21, 41, 42]. In addition, viruses have also evolved different strategies to manipulate or customize the UPR for their own benefit [43]. Many studies have reported that the life cycle of flaviviruses is associated with the UPR. For instance, Ambrose and Mackenzie et al. reported that ATF6-deficient cells infected with $\mathrm{WNV}_{\mathrm{KUN}}$ exhibit a decline in viral protein and infectious virion production. These cells also show increased eIF $2 \alpha$ phosphorylation and $\mathrm{CHOP}$ transcription, suggesting that decreases in $\mathrm{WNV}_{\text {KUN }}$ protein production may be attributed to the inability to manipulate the PERK-mediated response 
[30]. Furthermore, Yu et al. reported that induction of the IRE1 pathway by DENV infection protects cells against apoptosis, alleviates ER stress and facilitates virion production [44]. He et al. reported that classical swine fever virus (CSFV)-induced ER stress promotes viral replication, with a benefit from activation of IRE1-XBP1-GRP78 signalling [43]. These studies indicate the critical role of the UPR in viral infection. However, the ER stress and UPR signalling involved in TMUV-infected cells have not been fully explored. Here, we comprehensively examine the UPR initiated by TMUV infection and report for the first time that TMUV triggers activation of the PERK, IRE1 and ATF6 pathways in BHK-21 cells.

Due to their roles as molecular chaperones, GRP78 and GRP94 are used extensively as biological markers for the onset of ER stress and the UPR. Because the induction of GRP78 and GRP94 is regulated primarily at the transcriptional level, GRP78 and GRP94 mRNA abundance is commonly determined by real-time RT-PCR [45]. In our study, relative gene expression of GRP78 and GRP94 was significantly higher in TMUV-infected cells at $24 \mathrm{~h}$ post-infection compared to mock-infected cells. The observed induction of GRP78 and GRP94 is possibly due to the overwhelming expression of viral proteins exceeding normal ER folding capacity, thereby causing ER stress and activating the UPR. Using the viral overlay protein binding assay (VOPBA) and LC-MS/MS analysis, our previous study identified GRP78 as a receptor for TMUV on BHK-21 cells. Furthermore, antibody inhibition and siRNA-mediated knockdown of GRP78 inhibits TMUV infection in BHK-21 cells [46]. Taken together, these findings highlight the multiple critical roles of GRP78 in the life cycle of TMUV.

PERK and eIF2 $\alpha$ signalling is involved in the early stage of ER stress [47], and very early during TMUV infection, we observed continuously high levels of phosphorylated eIF $2 \alpha$, indicating activation of the PERK pathway early in infection. GADD34 mediates the dephosphorylation of eIF $2 \alpha$ in a negative feedback loop and subsequently promotes recovery from translational attenuation [11]. In this study, robustly enhanced expression of GADD34 was observed at 36 $\mathrm{h}$ post-infection. Consistent with this observation, phosphorylation of eIF $2 \alpha$ in TMUV-infected cells was suppressed after $36 \mathrm{~h}$ post-infection. Furthermore, at $48 \mathrm{~h}$ post-infection, the level of eIF $2 \alpha$ phosphorylation in TMUV-infected cells was lower than that in mock-infected cells. This lower level of eIF2 $\alpha$ phosphorylation indicates elevated translational initiation and higher overall level of protein synthesis at this time point, which are favourable for viral protein synthesis [48].
The UPR is often activated as a pro-survival signal to restore ER homeostasis. However, persistent stress results in switching of the UPR from a pro-survival signal to a pro-apoptotic signal and then to cell death if the damage becomes irreversible [49]. Our data demonstrate that TMUV infection induced robust and persistent expression of CHOP. Moreover, we found that TMUV infection activated the caspase- 3 protease in BHK-21 cells, which is consistent with a previous study reporting that TMUV triggers apoptosis and activates the caspase- 3 cascade in duck embryo fibroblasts (DEFs) as well as in Vero and BHK cells [50]. Indeed, activation of caspase and apoptosis appears to be characteristic of flavivirus infection. For example, WNV infection triggers caspase-3 activation and apoptosis both in vitro and in vivo [51]. JEV also initiates the caspase- 3 cascade and apoptosis in cultured cells [52], and DENV-induced apoptosis has been reported in diverse types of cells, including brain, epithelial and liver cells [53].

The transcription factor sXBP1 binds to the UPR element (UPRE) and to ERSEs in the promoter regions of target genes. sXBP1 induces a wide range of genes involved in the process of ER-associated degradation (ERAD), by which the ER directs the degradation of misfolded or inappropriate proteins. sXBP1 can also regulate genes encoding chaperones responsible for protein folding [54]. Thus, the IRE1 pathway restores ER homeostasis by enhancing protein-folding capacity and misfolded protein degradation [4]. Previous studies have shown that activation of the IRE1 pathway reduced flavivirus-induced cytotoxicity and allowed the virus to replicate more efficiently [4, 44]. During the UPR, expression of the $\mathrm{p} 58^{\mathrm{IPK}}$ gene is controlled by SXBP1 and connects two of the UPR branches, IRE1 and PERK. In turn, $\mathrm{p} 58^{\mathrm{IPK}}$ interacts with PERK and is serves as an inhibitor of eIF2 $\alpha$ [55]. Our data suggest that sXBP1 mRNA begins to accumulate starting at $24 \mathrm{~h}$ post-infection, and we also detected induction of $\mathrm{p} 58^{\mathrm{IPK}}$ in TMUV-infected cells at this time point. The functional consequence is that PERK-mediated eIF2 $\alpha$ phosphorylation is suppressed and that the IRE1 pathway is triggered by the accumulation of viral proteins and the formation of mature viral particles, consistent with a previous study [3].

According to our data, ATF6 expression and ATF6-mediated regulation of chaperones fluctuated from $12 \mathrm{~h}$ to $48 \mathrm{~h}$ post-infection. The results reveal that activation of the ATF6 pathway was transient and occurred early in TMUV infection (from $12 \mathrm{~h}$ to $24 \mathrm{~h}$ post-infection), suggesting that ATF6 pathway activation may not play a major role in TMUV-induced UPR [37]. The observation that the ATF6 pathway 
was transiently activated was consistent with a previous study of DENV. However, we report here that this activation occurred in the early stage of TMUV infection and ceased prior to activation of the IRE1 pathway. Peña and Harris reported that in DENV-infected cells, ATF6 induction was preceded by activation of the IRE1 pathway [3], and several different viruses, such as WNV and DENV, activate the ATF6 pathway to promote viral replication by regulating signal transduction and innate immune responses [30, 38]. Nevertheless, further investigation is needed to determine whether temporary activation of ATF6 affects TMUV replication during infection.

To explore the UPR in TMUV-infected DF-1 cells, expression of target genes related to the three UPR pathways was assessed, and the results showed that the IRE1 pathway was activated during the middle stage of infection ( $24 \mathrm{~h}$ postinfection) and that the ATF6 pathway was slightly activated in the late stage of infection ( $48 \mathrm{~h}$ post-infection). In contrast, no significant induction of ATF4 was observed in TMUV-infected DF-1 cells at any of the time points evaluated. Thus, the PERK pathway is possibly maintained in an inactive state, enabling translation of viral and cellular genes. However, Vattem and Wek et al. reported that the level of ATF4 expression might be induced by a translational mechanism [56]. Due to the lack of availability of antibodies against chicken UPR factors, the protein levels of upstream phospho-eIF $2 \alpha$ and downstream ATF4 were not examined. Thus, such a conclusion cannot be drawn at this time.

\section{Conclusions}

The present study is the first report that TMUV infection is able to activate the PERK, IRE1 and ATF6 signalling pathways of the UPR in a time-dependent manner. The PERK and ATF6 pathways are activated in the early stage of TMUV infection and the IRE1 pathway in the middle stage. Furthermore, the ATF6 pathway is activated transiently and then shut down before activation of the IRE pathway. UPR induction was also observed in TMUV-infected DF-1 cells, primarily through the IRE1 pathway, with some induction via the ATF6 pathway. These findings pave the way for further exploration of the roles that ER stress and UPR play during TMUV infection.

\section{Methods}

\section{Cells, viruses and antibodies}

The baby hamster kidney (BHK-21) and DF-1 cells were obtained from American Type Culture Collection. BHK-21 cells were cultured in RPMI-1640 (HyClone) containing $10 \%$ foetal calf serum (FCS, HyClone). DF-1 cells were grown in DMEM (Dulbecco's Modified Eagle's medium, Gibco) with 10\% FCS (HyClone). TMUV strain JS804 used in this study was isolated from an affected goose with ovary haemorrhage and an enlarged spleen and propagated in BHK-21 cells [1]. Viral titres were determined using a plaque-forming assay, as previously described [57]. Antibodies against phospho-eIF $2 \alpha$, eIF $2 \alpha$, anti-CHOP, p58 ${ }^{\mathrm{IPK}}$, calreticulin, ATF4 and PDI were obtained from Cell Signaling Technology. The anti-ATF6 antibody was purchased from Santa Cruz Biotechnology. Antibodies against GRP94, GRP78, GADD34, calnexin and a horseradish peroxidase (HRP)-labelled goat antimouse IgG antibody were obtained from Abcam. An HRP-labelled goat anti-rabbit IgG antibody was obtained from Invitrogen. The BeyoECL Plus Kit was purchased from Beyotime.

\section{RNA extraction and real-time RT-PCR detection}

Cells were harvested and lysed by Trizol reagent. Total RNA was then extracted by using RNA Purification Kit (Invitrogen) according to the manufacturer's instructions. $1 \mu \mathrm{g}$ of total RNA was used to synthesize complementary DNA by using RT SuperMix for qPCR (+gDNA wiper, Vazyme). Target genes were detected by real-time quantitative (q) PCR. Table 1 shows the primers used in this study.

\section{Western blot analysis}

Cells infected with TMUV (multiplicity of infection $(\mathrm{MOI})=3)$ or mock infected were lysed using cell lysis buffer for western blotting and IP containing $1 \mathrm{mM}$ phenylmethylsulfonyl fluoride (PMSF; Beyotime). Protein concentrations were determined by using BCA method (Beyotime). Equal amounts of protein were separated by $12 \%$ SDS-PAGE (sodium dodecyl sulfate polyacrylamide gel electrophoresis), followed by transferring proteins from gel to PVDF (polyvinylidene difluoride) membranes using the wet transfer method. The membranes were then blocked with 5\% bovine serum albumin (BSA) in PBST $(0.5 \%$ Tween-20 in phosphate-buffered saline) at $37^{\circ} \mathrm{C}$ for $2 \mathrm{~h}$ and subsequently incubated overnight with diluted primary antibodies at $4{ }^{\circ} \mathrm{C}$. The membranes were washed by PBST for three times and incubated with secondary antibodies for $1 \mathrm{~h}$ at $37^{\circ} \mathrm{C}$. After further washing, the protein bands were detected using a BeyoECL Plus Kit (Beyotime).

\section{Treatment of BHK-21 cells with a PERK inhibitor}

BHK-21 cells were treated with $1 \mu \mathrm{M}$ of the PERK inhibitor GSK2606414 (Selleck) for $1 \mathrm{~h}$ at $37^{\circ} \mathrm{C}$. Then GSK2606414 treated cells were infected with TMUV or mock infected as described above and cultured in fresh medium with $1 \mu \mathrm{M}$ of GSK2606414 or the corresponding 
Table 1 Primers used in this study

\begin{tabular}{|c|c|c|c|}
\hline Primer name & Sequence & Primer name & Sequence \\
\hline GRP78-F & 5'-TCATCGGACGCACTTGGAA-3' & Calreticulin-F & 5'-GGAGCCTGCCGTCTACTTC-3' \\
\hline GRP78-R & 5'-TAGTGAGAACCATGGCAGAA-3' & Calreticulin-R & 5'-GGTCTGGCCCTTGTTACTGA-3' \\
\hline GRP94-F & 5'-CCGAGTTTGATGGGAAGAGGTT-3' & ERp57-F & 5'-CTAGGACTGCCGATGGGATTGT-3' \\
\hline GRP94-R & 5'-GGCCACAAGAGCACAAGGAGAT-3' & ERp57-R & 5'-AGTTGCTGGCTGCTITTAGGAA-3' \\
\hline ATF4-F & $5^{\prime}$-AGCAAAACAAGACAGCAGCCACTA-3' & PDI-F & 5'-CCCCGGAGGAGGAGGACAAC-3' \\
\hline ATF4-R & 5'-TTGCCTTACGGACCTCCTCTATCA-3' & PDI-R & 5'-CACACCACGGGGCATAGAAC-3' \\
\hline GADD34-F & 5'-AGCAGCTGACCGAGGCAAGAG-3' & CAS3-F & 5'-GCCCAAACTCTTCATCATTC-3' \\
\hline GADD34-R & 5'-TTAGGGGCGGTCCAAGGTGA-3' & CAS3-R & 5'-TCGGCTTCCACTGGTATCTT-3' \\
\hline CHOP-F & 5'-AAGAGGAAGATCAAGGAAGAACTA-3' & CAS8-F & 5'-CCTCATCAATCGGCTGGAC-3' \\
\hline CHOP-R & 5'-CCATGCGGTCAATCAGAG-3' & CAS8-R & 5'-ATGACCCTGTAGGCAGAAACC-3' [58] \\
\hline XBP1-F & 5'-GAGAAGGCGCTGCGGAGGAAACTG-3' & CAS9-F & 5'-CTCGAGGCAGGGACTTAGACA-3' \\
\hline XBP1-R & 5'-GAGAAAGGGAGGCTGGTAAGGAAC-3' & CAS9-R & 5'-AAACTTGACACGGCATCCA-3' [59] \\
\hline P58-F & 5'-AGATGGCGACCCTGATAACTA-3' & BHK-GAPDHF & 5'-ACTTGGCACATGTCTGTATGC-3' \\
\hline P58-R & 5'-GACTGGGCTTCCTTCTCTTC-3' & BHK-GAPDHR & 5'-CACCAGCATCACCCCATTT-3' \\
\hline Calnexin-F & 5'-TGCCGAGCCAGGTGTAGTG-3' & DF1-GRP94-F & 5'-CTGAGAAGTTTGCCTTTCAAGCAG-3' \\
\hline Calnexin-R & 5'-ССТСТTCATCССССТTGTСТT-3' & DF1-GRP94-R & 5'-GCTCCTCATTACCAGCAAGAGCAT-3' [60] \\
\hline DF1-uXBP1-F & 5'-CAGCACTCAGACTACGTGTTCCTCTG-3' & DF1-sXBP1-F & 5'-GCTGAGTCCGCAGCAGG-3' \\
\hline DF1-UXBP1-R & 5'-CTGCCATCAGAATCCATGTG-3' [60] & DF1-sXBP1-R & 5'-CTGCCATCAGAATCCATGTG-3' [60] \\
\hline DF1-ATF4-F & 5'-CAATTGGCTCGCTGTGGACAGTTT-3' & DF1-GRP78-F & 5'-TGTAGCCTATGGTGCAGCTGTTCA-3' \\
\hline DF1-ATF4-R & 5'-ACGGTGGCTTCCAGATGTTCCATA-3' [60] & DF1-GRP78-R & 5'-ATGCCAAGTGTCAGAGGACACACA-3' [60] \\
\hline DF1-ACTINF & 5'-CTGTGCCCATCTATGAAGGCTA-3' & & \\
\hline DF1-ACTINR & 5'-ATTTCTCTCTCGGCTGTGGTG-3' & & \\
\hline
\end{tabular}

concentration of DMSO (solvent dimethylsulfoxide). Mock-infected cells were used as a control. At $24 \mathrm{~h}$ post-infection, cells were harvested and analyzed by western blot.

\section{Cell viability}

BHK-21 cells were treated with GSK2606414 as described above, and the Cell Counting Kit-8 (Dojindo) was used to measure cell viability according to the manufacturer's protocol.

\section{Measurement of caspase activity}

BHK-21 cells were infected with TMUV or mock infected as described above; mock-infected cells were used as a control. At $12 \mathrm{~h}, 24 \mathrm{~h}, 36 \mathrm{~h}$ and $48 \mathrm{~h}$ post infection, Cells were harvested for measurement of caspase-3, -8 and -9 activities using assay kits (Beyotime). Caspase activity is presented as a percentage of the control.

\section{Dual luciferase reporter assay}

Cells were grown in 6-well plates one day before transfection. On the day of transfection, $2 \mu \mathrm{g}$ of pGM-ATF6-Lu or pGM-ERSE-Lu (pGM-Lu vector, Genomeditech) and $1 \mu \mathrm{g}$ of pRL-TK vector (Promega) were mixed with Lipofectamine 2000 (Invitrogen) and added to BHK-21 cells. At $48 \mathrm{~h}$ post transfection, cells were infected with TMUV $(\mathrm{MOI}=3)$ or mock-infected. After another $12 \mathrm{~h}, 24 \mathrm{~h}, 36 \mathrm{~h}$ and $48 \mathrm{~h}$, the cells were lysed using a dual luciferase reporter gene assay kit (Beyotime), and activities of luciferase and Renilla luciferase were measured separately using the GloMax-Muti detection system (Promega). The relative fold induction of luciferase activity was calculated.

\section{Data analysis}

Data were analysed with Student's t test. The software Statistical Package for the Social Sciences (SPSS) was used. The $P$ value less than 0.05 was considered significant.

\section{Abbreviations}

ATF4: Activating transcription factor 4; ATF6: Activating transcription factor 6; BHK: Baby hamster kidney cells; BSA: Bovine Serum Albumin; CHOP: C/EBPhomologous protein; CSFV: Classical swine fever virus; DENV: Dengue virus: elF2a: eukaryotic translation initiation factor 2a; ER: Endoplasmic reticulum; ERAD: Endoplasmic reticulum-associated degradation; ERp57: Endoplasmic reticulum protein $57 \mathrm{kDa}$; ERSE: Endoplasmic reticulum stress-response element; GADD34: Growth arrest and DNA damage 34; GRP78: Glucose-related protein 78; GRP94: Glucose-related protein 94; HRP: Horseradish Peroxidase; IRE1: Inositol-requiring enzyme 1; JEV: Japanese encephalitis virus; MOI: multiplicity of infection; p58 $^{\mathrm{IPK}}$ : Protein kinase inhibitor $\mathrm{p} 58$; PBS: Phosphate buffered saline; PBST: Phosphate buffered saline with tween20; PDI: Protein disulfide isomerase; PERK: Protein kinase RNA-like endoplasmic reticulum kinase; PMSF: Phenylmethanesulfonyl fluoride; RT-PCR: Reverse transcription polymerase chain reaction; SD: Standard deviation; SDS-

PAGE: Sodium dodecyl sulfate polyacrylamide gel electrophoresis; TBEV: Tick- 
borne encephalitis virus; TMUV: Tembusu virus; UPR: Unfolded protein

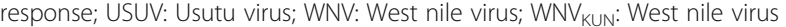
Kunjin strain; XBP1: X-boxing binding protein-1

\section{Acknowledgements}

We thank Mr. Yujie Tian and Miss Mengyao Wang for their assistance in cell culture.

\section{Funding}

The study was supported by Jiangsu Provincial Natural Science Foundation of China (No. BK20160064), National Natural Science Foundation of China (No. 31802222), National Key Research and Development Program of China (2017YFD0500804). The author confirm that the funders had no role in the study design, data collection and analysis, decision to publish, preparation of the manuscript or selection of this journal.

\section{Availability of data and materials}

Data can be obtained by contacting the corresponding author.

\section{Authors' contributions}

DMZ and YL designed experiments; DMZ carried out most of the experiments; JY, KKH, QTL and HLW helped with the experiments; JY, XMH, YZL and LJZ prepared the reagents; DMZ analyzed the data and wrote the manuscript. All authors read and approved the final manuscript.

\section{Ethics approval and consent to participate}

This study was approved by the ethical committee of Jiangsu Academy of Agricultural Sciences (approval No. SYXK-2015-0020).

\section{Consent for publication}

$$
\text { Not applicable. }
$$

\section{Competing interests}

The authors declare that they have no competing interests.

\section{Publisher's Note}

Springer Nature remains neutral with regard to jurisdictional claims in published maps and institutional affiliations.

\section{Author details \\ ${ }^{1}$ Institute of Veterinary Medicine, Jiangsu Academy of Agricultural Sciences, Jiangsu Province 210014, People's Republic of China. ${ }^{2}$ Key Laboratory of Veterinary Biological Engineering and Technology, Ministry of Agriculture, Nanjing, Jiangsu Province, People's Republic of China. ${ }^{3}$ Institute of Animal Sciences, Jiangsu Academy of Agricultural Sciences, Jiangsu Province, People's Republic of China.}

Received: 20 August 2018 Accepted: 14 January 2019 Published online: 22 January 2019

\section{References}

1. Huang X, Han K, Zhao D, Liu Y, Zhang J, Niu H, Zhang K, Zhu J, Wu D, Gao L, Li Y. Identification and molecular characterization of a novel flavivirus isolated from geese in China. Res Vet Sci. 2013;94:774-80.

2. Zhang W, Chen S, Mahalingam S, Wang M, Cheng A. An updated review of avian-origin Tembusu virus: a newly emerging avian Flavivirus. J Gen Virol. 2017;98(10):2413-20

3. Peña J, Harris E. Dengue virus modulates the unfolded protein response in a time-dependent manner. J Biol Chem. 2011:286(16):14226-36.

4. Yu C, Achazi K, Niedrig M. Tick-borne encephalitis virus triggers inositolrequiring enzyme 1 (IRE1) and transcription factor 6 (ATF6) pathways of unfolded protein response. Virus Res. 2013;178(2):471-7.

5. Domínguez-Martín E, Hernández-Elvira M, Vincent O, Coria R, Escalante R. Unfolding the endoplasmic reticulum of a social amoeba: Dictyostelium discoideum as a new model for the study of endoplasmic reticulum stress. Cell 2018;7(6). pii: E56

6. Winnay JN, Kahn CRPI. 3-kinase regulatory subunits as regulators of the unfolded protein response. Methods Enzymol. 2011:490:147-58.

7. Oslowski CM, Urano F. Measuring ER stress and the unfolded protein response using mammalian tissue culture system, vol. 490. 1st ed. New York: Elsevier Inc; 2011.
8. Cnop M, Toivonen S, Igoillo-Esteve M, Salpea P. Endoplasmic reticulum stress and elF2a phosphorylation: the Achilles heel of pancreatic $\beta$ cells. Mol Metab. 2017;6(9):1024-39.

9. Harding HP, Zhang Y, Ron D. Protein translation and folding are coupled by an endoplasmic-reticulum-resident kinase. Nature. 1999;397(6716):271-4.

10. Harding HP, Novoa I, Zhang Y, Zeng H, Wek R, Schapira M, Ron D. Regulated translation initiation controls stress-induced gene expression in mammalian cells. Mol Cell. 2000;6(5):1099-108.

11. Novoa I, Zeng H, Harding HP, Ron D. Feedback inhibition of the unfolded protein response by GADD34-mediated dephosphorylation of elF2alpha. J Cell Biol. 2001;153(5):1011-22.

12. Clarke R, Cook KL, Hu R, Facey CO, Tavassoly I, Schwartz JL, Baumann WT, Tyson JJ, Xuan J, Wang Y, Wärri A, Shajahan AN. Endoplasmic reticulum stress, the unfolded protein response, autophagy, and the integrated regulation of breast cancer cell fate. Cancer Res. 2012;72(6):1321-31.

13. Yoshida H, Haze K, Yanagi H, Yura T, Mori K. Identification of the cis-acting endoplasmic reticulum stress response element responsible for transcriptional induction of mammalian glucose-regulated proteins. Involvement of basic leucine zipper transcription factors. J Biol Chem. 1998; 273(50):33741-9.

14. Shen J, Prywes R. ER stress signaling by regulated proteolysis of ATF6. Methods. 2005;35(4):382-9.

15. Ye J, Rawson RB, Komuro R, Chen X, Davé UP, Prywes R, Brown MS, Goldstein JL. ER stress induces cleavage of membrane-bound ATF6 by the same proteases that process SREBPs. Mol Cell. 2000;6(6):1355-64.

16. Yoshida H, Matsui T, Yamamoto A, Okada T, Mori K. XBP1 mRNA is induced by ATF6 and spliced by IRE1 in response to ER stress to produce a highly active transcription factor. Cell. 2001;107(7):881-91.

17. Higa A, Chevet E. Redox signaling loops in the unfolded protein response. Cell Signal. 2012;24(8):1548-55.

18. Bertolotti A, Zhang Y, Hendershot LM, Harding HP, Ron D. Dynamic interaction of BiP and ER stress transducers in the unfolded-protein response. Nat Cell Biol. 2000;2(6):326-32.

19. Shen J, Chen $X$, Hendershot L, Prywes R. ER stress regulation of ATF6 localization by dissociation of BiP/GRP78 binding and unmasking of Golgi localization signals. Dev Cell. 2002;3(1):99-111.

20. Diwaker D, Mishra KP, Ganju L. Effect of modulation of unfolded protein response pathway on dengue virus infection. Acta Biochim Biophys Sin Shanghai. 2015;47(12):960-8.

21. Ambrose RL, Mackenzie JM. West Nile virus differentially modulates the unfolded protein response to facilitate replication and immune evasion. J Virol. 2011;85(6):2723-32

22. Medigeshi GR, Lancaster AM, Hirsch AJ, Briese T, Lipkin WI, Defilippis V, Früh K, Mason PW, Nikolich-Zugich J, Nelson JA. West Nile virus infection activates the unfolded protein response, leading to CHOP induction and apoptosis. J Virol. 2007;81(20):10849-60

23. $\mathrm{Su} \mathrm{HL}$, Liao $\mathrm{CL}$, Lin $\mathrm{YL}$. Japanese encephalitis virus infection initiates endoplasmic reticulum stress and an unfolded protein response. J Virol. 2002:76(9):4162-71.

24. Tan Z, Zhang W, Sun J, Fu Z, Ke X, Zheng C, Zhang Y, Li P, Liu Y, Hu Q, Wang $H$, Zheng Z. ZIKV infection activates the IRE1-XBP1 and ATF6 pathways of unfolded protein response in neural cells. J Neuroinflammation. 2018:15(1):275.

25. Blázquez AB, Escribano-Romero E, Merino-Ramos T, Saiz JC, Martín-Acebes MA. Stress responses in flavivirus-infected cells: activation of unfolded protein response and autophagy. Front Microbiol. 2014;5:266.

26. Blázquez AB, Escribano-Romero E, Merino-Ramos T, Saiz JC, Martín-Acebes MA. Infection with Usutu virus induces an autophagic response in mammalian cells. PLoS Negl Trop Dis. 2013;7(10):e2509.

27. Mukhopadhyay S, Kuhn RJ, Rossmann MG. A structural perspective of the flavivirus life cycle. Nat Rev Microbiol. 2005:3(1):13-22.

28. Ambrose R, Mackenzie JM. Flaviviral regulation of the unfolded protein response: can stress be beneficial? Future Virol. 2013:8(11):1095-109.

29. Limjindaporn T, Wongwiwat W, Noisakran S, Srisawat C, Netsawang J, Puttikhunt C, Kasinrerk W, Avirutnan P, Thiemmeca S, Sriburi R, Sittisombut $N$, Malasit P, Yenchitsomanus PT. Interaction of denque virus envelope protein with endoplasmic reticulum-resident chaperones facilitates dengue virus production. Biochem Biophys Res Commun. 2009;379(2):196-200.

30. Ambrose RL, Mackenzie JM. ATF6 signaling is required for efficient West Nile virus replication by promoting cell survival and inhibition of innate immune responses. J Virol. 2013;87(4):2206-14. 
31. Li S, Li X, Zhang L, Wang Y, Yu X, Tian K, Su W, Han B, Su J. Duck Tembusu virus exhibits neurovirulence in BALB/c mice. Virol J. 2013;10:260.

32. Axten JM, Medina JR, Feng Y, Shu A, Romeril SP, Grant SW, Li WH, Heerding DA, Minthorn E, Mencken T, Atkins C, Liu Q, Rabindran S, Kumar R, Hong X, Goetz A, Stanley T, Taylor JD, Sigethy SD, Tomberlin GH, Hassell AM, Kahler KM, Shewchuk LM, Gampe RT. Discovery of 7-methyl-5-(1-\{[3(trifluoromethyl)phenyl]acetyl\}-2,3-dihydro-1H-indol-5-yl)-7H-pyrrolo[2,3d]pyrimidin-4-amine (GSK2606414), a potent and selective first-in-class inhibitor of protein kinase $\mathrm{R}$ (PKR)-like endoplasmic reticulum kinase (PERK). J Med Chem. 2012;55(16):7193-207.

33. Zhu XJ, Gao SG, Li SQ, Shi ZG, Ma ZK, Zhu SS, Feng XS. Down-regulation of C/EBP homologous protein (CHOP) expression in gastric cardia adenocarcinoma: their relationship with clinicopathological parameters and prognostic significance. Clin Res Hepatol Gastroenterol. 2015;39(3):391-8.

34. van Schadewijk A, van't Wout EF, Stolk J, Hiemstra PS. A quantitative method for detection of spliced X-box binding protein-1 (XBP1) mRNA as a measure of endoplasmic reticulum (ER) stress. Cell Stress Chaperones 2012; 17(2):275-279.

35. Wang J, Kang R, Huang H, Xi X, Wang B, Wang J, Zhao Z. Hepatitis C virus core protein activates autophagy through EIF2AK3 and ATF6 UPR pathwaymediated MAP1LC3B and ATG12 expression. Autophagy. 2014;10(5):766-84.

36. Fung TS, Liao Y, Liu DX. Regulation of stress responses and translational control by coronavirus. Viruses 2016;8(7). pii: E184.

37. Lee YR, Kuo SH, Lin CY, Fu PJ, Lin YS, Yeh TM, Liu HS. Dengue virus-induced ER stress is required for autophagy activation, viral replication, and pathogenesis both in vitro and in vivo. Sci Rep. 2018;8(1):489.

38. Yin $H$, Zhao L, Jiang $X$, Li S, Huo H, Chen H. DEV induce autophagy via the endoplasmic reticulum stress related unfolded protein response. PLoS One. 2017;12(12):e0189704.

39. He B. Viruses, endoplasmic reticulum stress, and interferon responses. Cell Death Differ. 2006;13(3):393-403.

40. Martín-Acebes MA, Merino-Ramos T, Blázquez AB, Casas J, Escribano-Romero E, Sobrino F, Saiz JC. The composition of West Nile virus lipid envelope unveils a role of sphingolipid metabolism in flavivirus biogenesis. J Virol. 2014;88(20):12041-54.

41. Knowlton AA, Grenier M, Kirchhoff SR, Salfity M. Phosphorylation at tyrosine524 influences nuclear accumulation of HSP72 with heat stress. Am J Physiol Heart Circ Physiol. 2000;278(6):H2143-9.

42. Wu YP, Chang CM, Hung CY, Tsai MC, Schuyler SC, Wang RY. Japanese encephalitis virus co-opts the ER-stress response protein GRP78 for viral infectivity. Virol J. 2011;8:128.

43. He W, Xu H, Gou H, Yuan J, Liao J, Chen Y, Fan S, Xie B, Deng S, Zhang Y, Chen J, Zhao M. CSFV infection up-regulates the unfolded protein response to promote its replication. Front Microbiol. 2017:8:2129.

44. Yu CY, Hsu YW, Liao CL, Lin YL. Flavivirus infection activates the XBP1 pathway of the unfolded protein response to cope with endoplasmic reticulum stress. J Virol. 2006;80(23):11868-80.

45. Hong M, Lin MY, Huang JM, Baumeister P, Hakre S, Roy AL, Lee AS. Transcriptional regulation of the Grp78 promoter by endoplasmic reticulum stress: role of TFII-I and its tyrosine phosphorylation. J Biol Chem. 2005; 280(17):16821-8

46. Zhao D, Liu Q, Han K, Wang H, Yang J, Bi K, Liu Y, Liu N, Tian Y, Li Y. Identification of glucose-regulated protein 78 (GRP78) as a receptor in BHK-21 cells for duck tembusu virus infection. Front Microbiol. 2018;9:694.

47. Li J, Ni M, Lee B, Barron E, Hinton DR, Lee AS. The unfolded protein response regulator GRP78/BiP is required for endoplasmic reticulum integrity and stress-induced autophagy in mammalian cells. Cell Death Differ. 2008;15(9):1460-71.

48. Tardif KD, Mori K, Siddiqui A. Hepatitis C virus subgenomic replicons induce endoplasmic reticulum stress activating an intracellular signaling pathway. J Virol. 2002;76(15):7453-9.

49. Yoshida H, Matsui T, Hosokawa N, Kaufman RJ, Nagata K, Mori K. A timedependent phase shift in the mammalian unfolded protein response. Dev Cell. 2003 Feb;4(2):265-71.

50. Shaozhou W, Li C, Zhang Q, Meng R, Gao Y, Liu H, Bai X, Chen Y, Liu M, Liu $S$, Zhang $Y$. Duck tembusu virus and its envelope protein induce programmed cell death. Virus Genes. 2015;51(1):39-44.

51. Samuel MA, Morrey JD, Diamond MS. Caspase 3-dependent cell death of neurons contributes to the pathogenesis of West Nile virus encephalitis. J Virol. 2007;81(6):2614-23.
52. Lee CJ, Liao CL, Lin YL. Flavivirus activates phosphatidylinositol 3-kinase signaling to block caspase-dependent apoptotic cell death at the early stage of virus infection. J Virol. 2005;79(13):8388-99.

53. Courageot MP, Catteau A, Desprès P. Mechanisms of dengue virus-induced cell death. Adv Virus Res. 2003;60:157-86.

54. Cao SS, Kaufman RJ. Unfolded protein response. Curr Biol. 2012;22(16):R622-6.

55. Lee AH, Iwakoshi NN, Glimcher LH. XBP-1 regulates a subset of endoplasmic reticulum resident chaperone genes in the unfolded protein response. $\mathrm{Mol}$ Cell Biol. 2003;23(21):7448-59.

56. Vattem KM, Wek RC. Reinitiation involving upstream ORFs regulates ATF4 mRNA translation in mammalian cells. Proc Natl Acad Sci U S A. 2004; 101(31):11269-74.

57. Zhao D, Huang X, Liu Y, Han K, Zhang J, Yang J, Xie X, Li Y. Domain I and II from newly emerging goose tembusu virus envelope protein functions as a dominant-negative inhibitor of virus infectivity. Res Vet Sci. 2015;98:121-6.

58. Han YH, Zhang ZW, Su J, Zhang B, Li S, Xu SW. Effects of chicken selenoprotein W on H2O2-induced apoptosis in CHO-K1 cells. Biol Trace Elem Res. 2012;147(1-3):395-402.

59. Cholleti H, Paidikondala M, Munir M, Hakhverdyan M, Baule C. Equine arteritis virus induced cell death is associated with activation of the intrinsic apoptotic signalling pathway. Virus Res. 2013;171(1):222-6.

60. Neerukonda SN, Katneni UK, Bott M, Golovan SP, Parcells MS. Induction of the unfolded protein response (UPR) during Marek's disease virus (MDV) infection. Virology. 2018;522:1-12.
Ready to submit your research? Choose BMC and benefit from:

- fast, convenient online submission

- thorough peer review by experienced researchers in your field

- rapid publication on acceptance

- support for research data, including large and complex data types

- gold Open Access which fosters wider collaboration and increased citations

- maximum visibility for your research: over $100 \mathrm{M}$ website views per year

At BMC, research is always in progress.

Learn more biomedcentral.com/submissions 